\title{
Molecular Characterisation Reveals the Existence of a Hybridogenous Intermediary Form between Sweet Watermelon and Cow Melon Forms of Watermelon
}

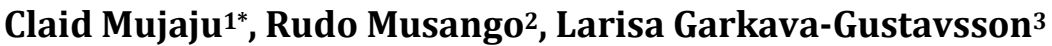 \\ ${ }^{1}$ Department of Research and Specialist Services, Research Services Division, Seed Services Institute, \\ Harare, Zimbabwe \\ ${ }^{2}$ Department of Research and Specialist Services, Research Services Division, Genetic Resources and Biotechnology Institute, \\ Harare, Zimbabwe \\ ${ }^{3}$ Department of Plant Breeding, Swedish University of Agricultural Sciences, Uppsala, Sweden \\ Email: *mujajuclaid@gmail.com
}

How to cite this paper: Mujaju, C., Musango, R. and Garkava-Gustavsson, L. (2018) Molecular Characterisation Reveals the Existence of a Hybridogenous Intermediary Form between Sweet Watermelon and Cow Melon Forms of Watermelon. American Journal of Plant Sciences, 9, 1245-1259.

https://doi.org/10.4236/ajps.2018.96092

Received: April 4, 2018

Accepted: May 22, 2018

Published: May 25, 2018

Copyright $\odot 2018$ by authors and Scientific Research Publishing Inc. This work is licensed under the Creative Commons Attribution International License (CC BY 4.0).

http://creativecommons.org/licenses/by/4.0/

\section{(c) (i) Open Access}

\begin{abstract}
Watermelon research in Southern Africa, has predominantly observed the clear existence of the sweet watermelon and cow melon forms of watermelon, cultivated on farm and even some occurring in the wild. Molecular characterization of 48 watermelon accessions collected from National Genebank of Zimbabwe using 9 SSR markers generated a total of 49 putative alleles. The average number of alleles detected by each primer was 5.4. Analysis of molecular variance within and among accessions of watermelons revealed that only $39 \%$ of the total variation resides between these two groups (cow-melons and sweet watermelons), $24 \%$ between accession within groups and $37 \%$ within accessions. Multivariate analyses employed provide evidence of the existence of introgression between sweet water melons and cow melons, as reflected by some accessions of cow melons, clustering into a hybridogenous group. Most of watermelon accessions within the hybridogenous group [A (II)] were collected from drier communal areas, while those accessions within the cow melon group [A (I)] are mostly from research centers. The separation of cow melons into distinct groups could be indicative of a possible formation of an isolated evolutionary unit.
\end{abstract}

\section{Keywords}

Sweet Watermelon, Cow Melons, SSR, Hybridogenous, Characterization, Genetic Diversity 


\section{Introduction}

Watermelon is an economically important vegetable crop of the family Cucubitaceae, subfamily Cucubitoideae, tribe Benincaseae and subtribe Benincainae [1]. The family consists of 119 genera with 825 species [2]. The species Citrullus lanatus (Thunberg) Matsumura and Nakai consist of two botanical varieties: $C$. lanatus var. lanatus, the cultivated watermelon widely grown around the world and $C$. lanatus var. citroides, a wild form found in Southern Africa and also cultivated for feeding animals [3]. Previously, the cultivated species C. lanatus included three subspecies: 1) lanatus, 2) vulgaris with two varieties, var. vulgaris and var. cordophanus, and 3) mucosospermus [4].

The recent molecular phylogenetic analysis found that the three subspecies of C. lanatus were in fact unrelated species [5]. In their work, [5] and [6] echoed another suggestion that the genus Citrullus includes seven species: 1) C. lanatus with the sweet watermelon group as $C$. lanatus subsp. vulgaris, 2) $C$. amarus, also known as $C$. lanatus var. caffrorum or $C$. lanatus var. citroides, 3) C. mucosospermus, the "egusi" melon, previously treated as a subspecies of $C$. lanatus, 4) $C$. colocynthis, which is perennial and growing in northern Africa and adjacent Asia, 5) C. ecirrhosus, a tendril-less South African endemic, another perennial wild species, 6) C. rehmii, an annual wild species and 7) $C$. naudininus from the Namib-Kalahari regions.

According to [1], C. lanatus var. lanatus (sweet watermelon) and C. lanatus var cirtoides (cow-melons), are the two major forms of watermelons that are native to southern Africa countries such as Botswana, Malawi, Republic of South Africa, Zambia and Zimbabwe. C. lanatus var. citroides is often cultivated in rural homes for human consumption through Nhopi (porridge made from their pulp), and stock feed [7]. The C. lanatus var. lanatus is cultivated extensively and it emerged as results of human intervention, selecting for reddish colour and sweetness. Both species are extensively distributed across Zimbabwe.

Currently several molecular markers have been used to assess the genetic diversity of watermelon. ISSR [8], SSR [9]-[16], SRAP [11] [17], EST-PCR [18], and HFO-TAG markers [19] have been used to estimate the genetic relationship among cultivated watermelons and different Citrullus species. Studies by [13] and [19] revealed low levels of DNA polymorphism among cultivated watermelons but high genetic diversity among the Citrullus subspecies. [20] and [21] also revealed very low genetic diversity in cultivated watermelon. In [22], wide variation was found within the local landraces whereas the genetic basis of the commercial type appeared to be narrow. The objective of the study is to use the SSR markers to examine the genetic relationships among some cultivated Zimbabwean watermelon genetic resources stored in the National Genebank, many of which were not part of the previous studies. Apart from assessing genetic relatedness, the study of the remaining watermelon accessions was done to complete the molecular characterization of the watermelon accessions from National Genebank of Zimbabwe. 


\section{Material and Methods}

\subsection{Plant Materials and DNA Extraction}

A total of 48 accessions of Citrullus lanatus were obtained from National Genebank of Zimbabwe housed at the Genetic Resources and Biotechnology Institute of Zimbabwe. The accessions were originally collected from across the country in Zimbabwe (Table 1) and were not included in previous studies. The DNA extraction and SSR analysis was carried out at SLU Alnarp, Sweden. Five plants

Table 1. List of watermelon material with their place of collection (groups according to multivariate analysis).

\begin{tabular}{|c|c|c|c|}
\hline \multicolumn{2}{|c|}{ GROUP A } & \multirow{2}{*}{\multicolumn{2}{|c|}{ GROUP B Sweet watermelon }} \\
\hline \multicolumn{2}{|c|}{ SUB I Cow-melons } & & \\
\hline Accessions No. & Place of collection & Accessions No. & Place of collection \\
\hline CWM176 & HRI & SWM1027 & CBI \\
\hline CWM180 & HRI & SWM2703 & Gwanda \\
\hline CWM2706 & Gwanda & SWM1029 & CBI \\
\hline CWM184 & HRI & SWM2705 & Gwanda \\
\hline CWM2699 & Gwanda & SWM325 & CTDO \\
\hline CWM2708 & Gwanda & SWM2605 & Muzarabani \\
\hline CWM182 & HRI & SWM2630 & Murehwa \\
\hline CWM187 & HRI & SWM2633 & Chiredzi \\
\hline CWM185 & HRI & SWM1012 & CBI \\
\hline CWM183 & HRI & SWM2634 & Chiredzi \\
\hline CWM186 & HRI & SWM1014 & CBI \\
\hline CWM1030 & CBI & SWM1023 & CBI \\
\hline \multicolumn{2}{|c|}{ SUB II Cow-melons } & SWM1008 & CBI \\
\hline Accessions No. & Place of collection & SWM2684 & Gutu \\
\hline CWM2688 & Chivi & SWM1019 & CBI \\
\hline CWM2703 & Gwanda & SWM1025 & CBI \\
\hline CWM2722 & Zvishavane & SWM1018 & CBI \\
\hline CWM2725 & Zvishavane & SWM1021 & CBI \\
\hline CWM2707 & Gwanda & SWM1024 & CBI \\
\hline CWM2711 & Gwanda & SWM1028 & CBI \\
\hline CWM2729 & Zvishavane & SWM1011 & CBI \\
\hline CWM2709 & Gwanda & SWM2685 & Chilonga \\
\hline CWM531 & HRI & SWM2731 & Mashava \\
\hline CWM2691 & Dhonza & SWM1015 & CBI \\
\hline CWM2723 & Zvishavane & SWM2025 & CBI \\
\hline
\end{tabular}

*The first three letters and numbers correspond to the accession number, CWM refers Cow-melon and SWM is Sweet watermelon. HRI and CBI is the name of the institute that donated the accession which is the Horticulture Research Institute and Crop Breeding Institute respectively. 
from each accession were planted in pots in the greenhouse at $25^{\circ} \mathrm{C}$ at SLU-Alnarp, Sweden. Young leaves were collected from each watermelon genotype and immediately frozen in liquid nitrogen and stored at $-80^{\circ} \mathrm{C}$. High molecular weight genomic DNA was extracted from the leaf samples using the Qiagen Plant Mini Kit. DNA concentration was measured with a Nan Drop, ND 100 spectrophotometer (Nano Drop Technologies, Inc. Wilmington, DE, USA) and gel electrophoresis. DNA was diluted in water to a final concentration of $50 \mathrm{ng} / \mu \mathrm{L}$ and stored at $-20^{\circ} \mathrm{C}$.

\subsection{SSR Analyses}

Nine SSR primer pairs originally published by [23] and previously employed by [1] [3] in Zimbabwe watermelon accessions, were used in this study (Table 2). These primers were previously screened and have been used to provide a basis for comparison across all watermelon accessions for future Zimbabwe.

Amplification reactions were performed in $10 \mu \mathrm{L}$, containing 0.1 of $5 \mathrm{U} \cdot \mu \mathrm{L}^{-1}$ Taq DNA polymerase, $0.1 \mu \mathrm{l}$ of each primer $(100 \mu \mathrm{M})$ (Eurofins MWG Operon

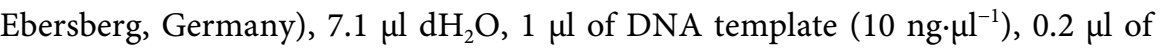
$10 \mathrm{mM}$ dNTPs, $0.4 \mu \mathrm{l}$ of $25 \mathrm{mM} \mathrm{MgCl}$ and $1 \mu \mathrm{l}$ of reaction buffer (Thermo Fisher Scientific, Surrey, UK). The amplification was performed in a Master Gradient thermal cycler (Eppendorf) using a program consisting of an initial denaturation step of $94^{\circ} \mathrm{C}, 30 \mathrm{~s}$ at appropriate annealing temperature, $30 \mathrm{~s}$ at $72^{\circ} \mathrm{C}$, and a final extension of $7 \mathrm{~min}$ at $72^{\circ} \mathrm{C} .4 .0 \mu \mathrm{l}$ of the reaction volume from ten randomly selected samples was checked for successful amplification on $2 \%$ agarose gels with subsequent visualization of fragment using UV illumination. The size of the amplified products was calculated based on an internal standard (500ROXTM Size Standard; Applied Biosystems) using GeneMarker Software Version 1.85 (SoftGenetics, State College, PA, USA).

Table 2. Description of SSR loci used in the study.

\begin{tabular}{cccccc}
\hline SSR Marker & SSR Motif* $^{*}$ & AT $\left({ }^{\circ} \mathrm{C}\right)$ & AN & Fragment size or range & Colour \\
\hline MCPI-07 & $(\mathrm{AAG})_{9}$ & 55 & 6 & $232-255$ & Hex \\
MCPI-28 & $(\mathrm{AAG})_{9}$ & 55 & 9 & $240-289$ & Fam \\
MCPI-03 & $(\mathrm{TG})_{8}$ & 55 & 9 & $212-254$ & Fam \\
MCPI-32 & $(\mathrm{AAG})_{5}(\mathrm{ATC})_{8}$ & 55 & 10 & $245-282$ & Fam \\
MCPI-21 & $(\mathrm{AG})_{11}$ & 55 & 14 & $176-234$ & Hex \\
MCPI-12 & $(\mathrm{AAG})_{7} \mathrm{~N}_{69}(\mathrm{AT})_{26}$ & 55 & 16 & $214-332$ & Hex \\
MCPI-13 & $(\mathrm{AG})_{25}$ & 55 & 19 & $184-235$ & Hex \\
MCPI-14 & $(\mathrm{AAT})_{15}$ & 55 & 26 & $218-291$ & Fam \\
MCPI-37 & $(\mathrm{AAT})_{9}$ & 55 & 27 & $160-270$ & Fam \\
\hline
\end{tabular}

*SSR motifs (markers) described by [23]. 


\subsection{Data Analysis}

For single-locus evaluations of the SSR data, all SSR fragments were scored as allele size at each locus. The polymorphic information content (PIC) values for each locus were then calculated according to the formula:

$$
\mathrm{PIC}=1-\sum P_{i}^{2}
$$

where $P_{i}$ was the frequency of the $i$-th allele [24].

Data from the nine SSR loci from 48 accessions were then collected into multi-locus profiles of allele size, and the resultant data matrix was used for subsequent analyses. The programme, GenAIEx 6 [25] was used to calculate the percentage of polymorphic alleles within each accession, the allele-specific F-statistics $\left(F_{I S}\right)$, the expected heterozygosity $\left(H_{E}\right)$, the observed heterozygosity $\left(H_{O}\right)$, and Shannon's index of diversity $(I)$. Testing short allele dominance was carried out by regression of allele-specific $F_{I S}$ statistics on allele sizes. A significant negative slope indicated that short allele dominance may be suspected [26].

$G_{S T}$ values for genetic differentiations among accessions were calculated according to the formula:

$$
G_{S T}=\left(H_{T}-H_{S}\right) / H_{T}
$$

where $H_{T}$ was the total genetic diversity and $H s$ was the mean within-accession diversity [27].

Analyses of molecular variance (AMOVA), to estimate the partitioning of genetic variation at different levels, between sweet watermelons and cow-melons, between and within accessions, and between the USA and five African countries, were calculated using Arlequin Version 3.0 [28]. AMOVA calculations yielded an independent estimate (QST) of accession differentiation for comparison with Nei's $G_{S T}$. Levels of similarity among and within accessions were also investigated using multivariate methods. Nei's genetic similarity matrix generated by GenAIEx 6 was used as an input matrix to construct a UPGMA cluster analysis with NSTSYS-pc Version 2.2 [29]. The distortion effect was estimated using a cophenetic correlation analysis. As a means to verify groups derived from the cluster analysis, and being more useful for data that lack a strong hierarchical structure, a principal co-ordinate analysis (PCO) was computed in GenAIEx 6.

\section{Results}

\subsection{Polymorphism and Allelic Diversity of SSR Markers}

Primer sequence information and the range of amplified product sizes among the watermelon accessions are presented in Table 3. The 9 SSR markers generated a total of 49 putative alleles for the sampled watermelon population. The number of alleles detected by each primer set ranged from 2 to 13, with an average of 5.4 .

The total number of alleles for the marker MCPI-07-M13 and MCPI-28-M13 loci produced the highest number of alleles 13 and 10 respectively, while the least marker MCPI-14-M13 produced only two alleles. PIC values ranged 
Table 3. Description of SSR loci used and PIC values.

\begin{tabular}{|c|c|c|c|c|c|c|c|c|}
\hline Primer & SSR Motif & $\operatorname{AT}\left({ }^{\circ} \mathrm{C}\right)$ & $\begin{array}{c}\text { Range of } \\
\text { fragment sizes }\end{array}$ & AN & $F_{I S}$ & $H_{o}$ & $H_{e}$ & PIC \\
\hline MCPI-07 & $(\mathrm{AAG}) 9$ & 55 & $216-281$ & 13 & 0.017 & 0.231 & 0.235 & 0.989 \\
\hline MCPI-28 & $(\mathrm{AAG}) 9$ & 55 & $178-226$ & 10 & 0.316 & 0.125 & 0.182 & 0.970 \\
\hline MCPI-21 & $(\mathrm{AG}) 11$ & 55 & $131-231$ & 6 & -0.928 & 0.949 & 0.492 & 0.955 \\
\hline MCPI-32 & (AAG)5(ATC)8 & 55 & $164-238$ & 6 & -0.658 & 0.148 & 0.089 & 0.943 \\
\hline MCPI-37 & $(\mathrm{AAG}) 9$ & 55 & $234-254$ & 3 & -0.970 & 1.000 & 0.508 & 0.847 \\
\hline MCPI-03 & (TG)8 & 55 & $192-207$ & 3 & -0.965 & 0.279 & 0.142 & 0.837 \\
\hline MCPI-13 & (AG)25 & 55 & $280-289$ & 3 & -0.190 & 0.030 & 0.025 & 0.833 \\
\hline MCPI-12 & (AAG)7N69(AT)26 & 55 & $177-218$ & 3 & 0.213 & 0.020 & 0.025 & 0.791 \\
\hline MCPI-14 & $(\mathrm{AAT}) 15$ & 55 & $266-269$ & 2 & -0.784 & 0.179 & 0.100 & 0.735 \\
\hline Mean & & & - & 5.444 & -0.439 & 0.329 & 0.200 & 0.878 \\
\hline
\end{tabular}

${ }^{*}$ SSR motifs (markers) described by [23], AT, annealing temperature; AN, total number of polymorphic alleles for each primer pair present in accessions; $F_{I S}$ allele-specific F-statistics for all accessions; $H_{o}$, observed heterozygosity; $H_{e}$, expected heterozygosity; PIC, polymorphic information content

between 0.73 (for marker MCPI-14-M13) and 0.98 (for marker MCPI-07-M13) with a mean 0.87 . The observed heterozygosity $\left(\mathrm{H}_{\mathrm{o}}\right)$ values ranged from 0.025 (MCPI-12-M13) to 1.00 (MCPI-37-M13), with a mean of 0.329. Expected heterozygosity $\left(\mathrm{H}_{\mathrm{e}}\right)$, as a measure of allelic diversity at a locus, ranged from 0.025 (MCPI-12-M13 and MCPI-13-M13) to 0.50 (MCPI-37-M13) with a mean of 0.20 .

Fixation index (F) exhibited contrasting ranging from -0.97 to 0.31 with a mean of -0.43 . F represents the average deviation of the population's genotypic proportions from Hardy-Weinberg equilibrium for a locus and the values ranged from 0 to 1 . A negative $\mathrm{F}$ value represents an excess of heterozygotes. MCPI-37-M13, 50\% of the citron watermelon landraces are expected to be heterozygous at the specific locus under random mating conditions; however $100 \%$ of the genotypes at this locus were heterozygotes. This may be due to the high outcrossing nature of citron watermelon or mutation as at that specific locus (Table 4).

Analysis of molecular variance (AMOVA) within and among the 48 accessions revealed that $39 \%$ of the total variation resided between the two major groups (i.e., cow-melon and sweet watermelon), $24 \%$ between accessions within groups, and $37 \%$ within accessions (Table 5). The overall $\mathrm{G}_{\mathrm{ST}}$ for between-accession differentiation was 0.67 , slightly higher than the AMOVA value of 0.63. Separate calculations for differentiation among cow-melon $\left(\mathrm{G}_{\mathrm{ST}}=0.55\right.$; $\left.\Phi_{\mathrm{ST}}=0.54\right)$ and among sweet watermelon accessions $\left(\mathrm{G}_{\mathrm{ST}}=0.44 ; \Phi_{\mathrm{ST}}=0.41\right)$, respectively, produced slightly lower values for the former compared to the latter. 
Table 4. Within-accession genetic variation in watermelons collections in Zimbabwe.

\begin{tabular}{|c|c|c|c|c|c|}
\hline Pop & NPL & $\% \mathrm{PL}$ & $H_{o}$ & $H_{e}$ & $I$ \\
\hline \multicolumn{6}{|c|}{ Cow melons } \\
\hline CWM176 & 5.000 & $44.44 \%$ & $0.378(0.161)$ & $0.204(0.082)$ & $0.302(0.120)$ \\
\hline CWM180 & 5.000 & $55.56 \%$ & $0.467(0.160)$ & $0.278(0.093)$ & $0.438(0.159)$ \\
\hline CWM182 & 5.000 & $33.33 \%$ & $0.222(0.147)$ & $0.147(0.075)$ & $0.210(0.106)$ \\
\hline CWM183 & 5.000 & $44.44 \%$ & $0.311(0.146)$ & $0.178(0.077)$ & $0.258(0.108)$ \\
\hline CWM184 & 4.000 & $22.22 \%$ & $0.222(0.147)$ & $0.111(0.073)$ & $0.154(0.102)$ \\
\hline CWM185 & 6.000 & $44.44 \%$ & $0.222(0.147)$ & $0.173(0.073)$ & $0.254(0.104)$ \\
\hline CWM186 & 5.000 & $22.22 \%$ & $0.222(0.147)$ & $0.111(0.073)$ & $0.154(0.102)$ \\
\hline CWM187 & 5.000 & $22.22 \%$ & $0.222(0.147)$ & $0.111(0.073)$ & $0.154(0.102)$ \\
\hline CWM2688 & 1.000 & $33.33 \%$ & $0.333(0.167)$ & $0.167(0.083)$ & $0.231(0.116)$ \\
\hline CWM2691 & 4.000 & $55.56 \%$ & $0.333(0.167)$ & $0.302(0.097)$ & $0.455(0.150)$ \\
\hline CWM2699 & 5.000 & $44.44 \%$ & $0.267(0.141)$ & $0.204(0.084)$ & $0.321(0.131)$ \\
\hline CWM2703 & 3.000 & $44.44 \%$ & $0.333(0.167)$ & $0.216(0.086)$ & $0.302(0.119)$ \\
\hline CWM2706 & 2.000 & $44.44 \%$ & $0.333(0.144)$ & $0.222(0.090)$ & $0.332(0.138)$ \\
\hline CWM2707 & 5.000 & $55.56 \%$ & $0.356(0.148)$ & $0.260(0.093)$ & $0.423(0.156)$ \\
\hline CWM2708 & 5.000 & $55.56 \%$ & $0.356(0.148)$ & $0.222(0.078)$ & $0.336(0.113)$ \\
\hline CWM2709 & 1.000 & $44.44 \%$ & $0.444(0.176)$ & $0.222(0.088)$ & $0.308(0.122)$ \\
\hline CWM2711 & 5.000 & $44.44 \%$ & $0.311(0.146)$ & $0.244(0.099)$ & $0.395(0.167)$ \\
\hline CWM2722 & 4.000 & $33.33 \%$ & $0.333(0.167)$ & $0.177(0.089)$ & $0.262(0.134)$ \\
\hline CWM2723 & 4.000 & $11.11 \%$ & $0.111(0.111)$ & $0.056(0.056)$ & $0.077(0.077)$ \\
\hline CWM2725 & 4.000 & $33.33 \%$ & $0.333(0.167)$ & $0.167(0.083)$ & $0.231(0.116)$ \\
\hline CWM2729 & 1.000 & $44.44 \%$ & $0.444(0.176)$ & $0.222(0.088)$ & $0.308(0.122)$ \\
\hline CWM531 & 5.000 & $66.67 \%$ & $0.333(0.137)$ & $0.331(0.089)$ & $0.508(0.142)$ \\
\hline CWM1030 & 4.000 & $55.56 \%$ & $0.444(0.149)$ & $0.271(0.086)$ & $0.378(0.120)$ \\
\hline Mean & & $41.55 \%$ & $0.319(0.160)$ & $0.200(0.088)$ & $0.295(0.130)$ \\
\hline \multicolumn{6}{|c|}{ Sweet watermelons } \\
\hline SWM1008 & 5.000 & $33.33 \%$ & $0.267(0.145)$ & $0.149(0.076)$ & $0.225(0.113)$ \\
\hline SWM1011 & 5.000 & $33.33 \%$ & $0.244(0.144)$ & $0.131(0.072)$ & $0.190(0.101)$ \\
\hline SWM1012 & 5.000 & $44.44 \%$ & $0.356(0.152)$ & $0.236(0.094)$ & $0.346(0.142)$ \\
\hline SWM1014 & 2.000 & $22.22 \%$ & $0.222(0.147)$ & $0.111(0.073)$ & $0.154(0.102)$ \\
\hline SWM1015 & 4.000 & $66.67 \%$ & $0.556(0.160)$ & $0.299(0.080)$ & $0.423(0.111)$ \\
\hline SWM1018 & 2.000 & $44.44 \%$ & $0.389(0.162)$ & $0.208(0.083)$ & $0.294(0.117)$ \\
\hline SWM1019 & 4.000 & $44.44 \%$ & $0.361(0.162)$ & $0.219(0.087)$ & $0.305(0.120)$ \\
\hline SWM1021 & 3.000 & $55.56 \%$ & $0.481(0.168)$ & $0.265(0.089)$ & $0.393(0.133)$ \\
\hline SWM1023 & 2.000 & $33.33 \%$ & $0.333(0.167)$ & $0.167(0.083)$ & $0.231(0.116)$ \\
\hline SWM1024 & 5.000 & $55.56 \%$ & $0.467(0.170)$ & $0.242(0.084)$ & $0.344(0.116)$ \\
\hline
\end{tabular}




\section{Continued}

\begin{tabular}{cccccc}
\hline SWM1025 & 1.000 & $33.33 \%$ & $0.333(0.167)$ & $0.167(0.083)$ & $0.231(0.116)$ \\
SWM1027 & 2.000 & $33.33 \%$ & $0.333(0.167)$ & $0.167(0.083)$ & $0.231(0.116)$ \\
SWM1028 & 2.000 & $66.67 \%$ & $0.556(0.176)$ & $0.347(0.088)$ & $0.501(0.131)$ \\
SWM1029 & 3.000 & $66.67 \%$ & $0.519(0.158)$ & $0.284(0.077)$ & $0.408(0.107)$ \\
SWM2025 & 4.000 & $44.44 \%$ & $0.361(0.162)$ & $0.191(0.081)$ & $0.273(0.113)$ \\
SWM2605 & 5.000 & $55.56 \%$ & $0.378(0.147)$ & $0.264(0.087)$ & $0.435(0.152)$ \\
SWM2630 & 1.000 & $22.22 \%$ & $0.222(0.147)$ & $0.111(0.073)$ & $0.154(0.102)$ \\
SWM2633 & 4.000 & $55.56 \%$ & $0.361(0.162)$ & $0.267(0.085)$ & $0.390(0.123)$ \\
SWM2634 & 5.000 & $44.44 \%$ & $0.311(0.146)$ & $0.211(0.084)$ & $0.326(0.132)$ \\
SWM2684 & 5.000 & $22.22 \%$ & $0.222(0.147)$ & $0.111(0.073)$ & $0.154(0.102)$ \\
SWM2685 & 5.000 & $22.22 \%$ & $0.222(0.147)$ & $0.111(0.073)$ & $0.154(0.102)$ \\
SWM2703 & 6.000 & $66.67 \%$ & $0.296(0.138)$ & $0.270(0.074)$ & $0.440(0.120)$ \\
SWM2705 & 2.000 & $22.22 \%$ & $0.222(0.147)$ & $0.111(0.073)$ & $0.154(0.102)$ \\
SWM2731 & 2.000 & $22.22 \%$ & $0.222(0.147)$ & $0.125(0.083)$ & $0.193(0.131)$ \\
SWM325 & 5.000 & $44.44 \%$ & $0.222(0.147)$ & $0.236(0.094)$ & $0.346(0.142)$ \\
Mean & & $42.22 \%$ & $0.338(0.155)$ & $0.200(0.081)$ & $0.292(0.118)$ \\
Grand Mean & & $41.90 \%$ & $0.329(0.022)$ & $0.200(0.012)$ & $0.293(0.017)$ \\
\hline
\end{tabular}

Other acronyms or symbols used: NPL, number of plants sampled; \%PL, percentage polymorphic alleles; $H_{o}$, observed heterozygosity; $H_{e}$ expected heterozygosity; $I$, Shannon's index. Standard errors are indicated in parenthesis showing the sampling error of the mean.

Table 5. Partitioning of genetic variation using $\mathrm{F}_{\mathrm{ST}}$ and AMOVA on SSR data taking into account (a) no prior grouping of accessions, and (b, c) grouping into two major forms (cow-melons and sweet watermelons).

\begin{tabular}{lc}
\multicolumn{1}{c}{ Source of Variation } & SSR \\
\hline (a) Partitioning all accessions & \\
$\mathrm{G}_{\mathrm{ST}}$ & 0.670 \\
$\Phi_{\mathrm{ST}}$ & 0.634 \\
(b) Partitioning with two major forms of cow-melons and sweet watermelons & \\
Between group diversity (AMOVA) & $39 \%^{*}$ \\
Between accessions within groups (AMOVA) & $24 \%^{*}$ \\
Within accession diversity (AMOVA) & $37 \%^{*}$ \\
(c) Partitioning per each major form & \\
Cow-melons & \\
$\mathrm{G}_{\mathrm{ST}}$ & 0.545 \\
$\Phi_{\mathrm{ST}}$ & 0.541 \\
Sweet watermelons $_{\mathrm{G}_{\mathrm{ST}}}$ & \\
$\Phi_{\mathrm{ST}}$ & 0.435 \\
\hline
\end{tabular}

${ }^{*}$ Significant at $1 \%, \mathrm{P}<0.01$. 


\subsection{Multivariate Analyses}

A dendrogram using UPGMA analysis was constructed based on the corresponding genetic similarity coefficient among the tested 25 sweet watermelons and 23 cow melon populations (Table 2). In this study, all the Citrullus species were grouped into two main clusters, with a similarity index of $48 \%$, for the $C i$ trullus lanatus forms of cow melons and sweet watermelons.

The cow melon cluster was further subdivided into two subgroups; with subgroup A (I) consisting of 12 cow melon accessions and the second subgroup A (II) consisted of 11 samples of cow melons (Figure 1 and Figure 2). From the cluster analysis, the sub I cluster the accession were predominantly collected from Horticulture Research Institute. Sub II of the group A the accessions were collected from parts of Zimbabwe located close together and sharing boundaries, i.e., Zvishavane, Gwanda, Chivi and Dhonza. The group B consisted of sweet watermelons; the accessions were mainly collected from Crop Breeding Institute and a few from Gwanda, Murehwa, Chiredzi, Chilonga and Mashava. The PCA (Figure 2) also showed the same grouping of these accessions into three clusters.

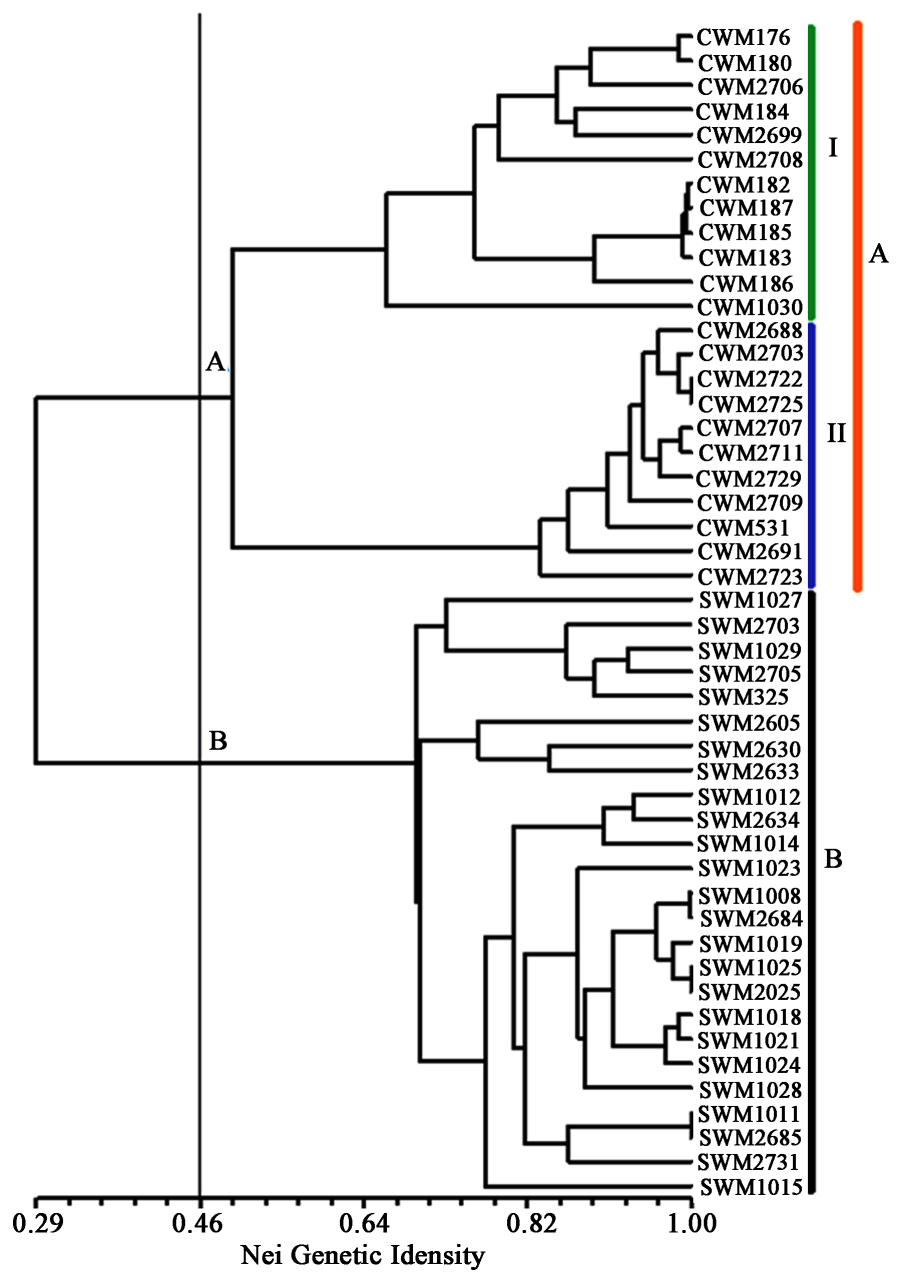

Figure 1. Dendrogram of watermelon accessions using UPMA based on Nei's genetic identity. 


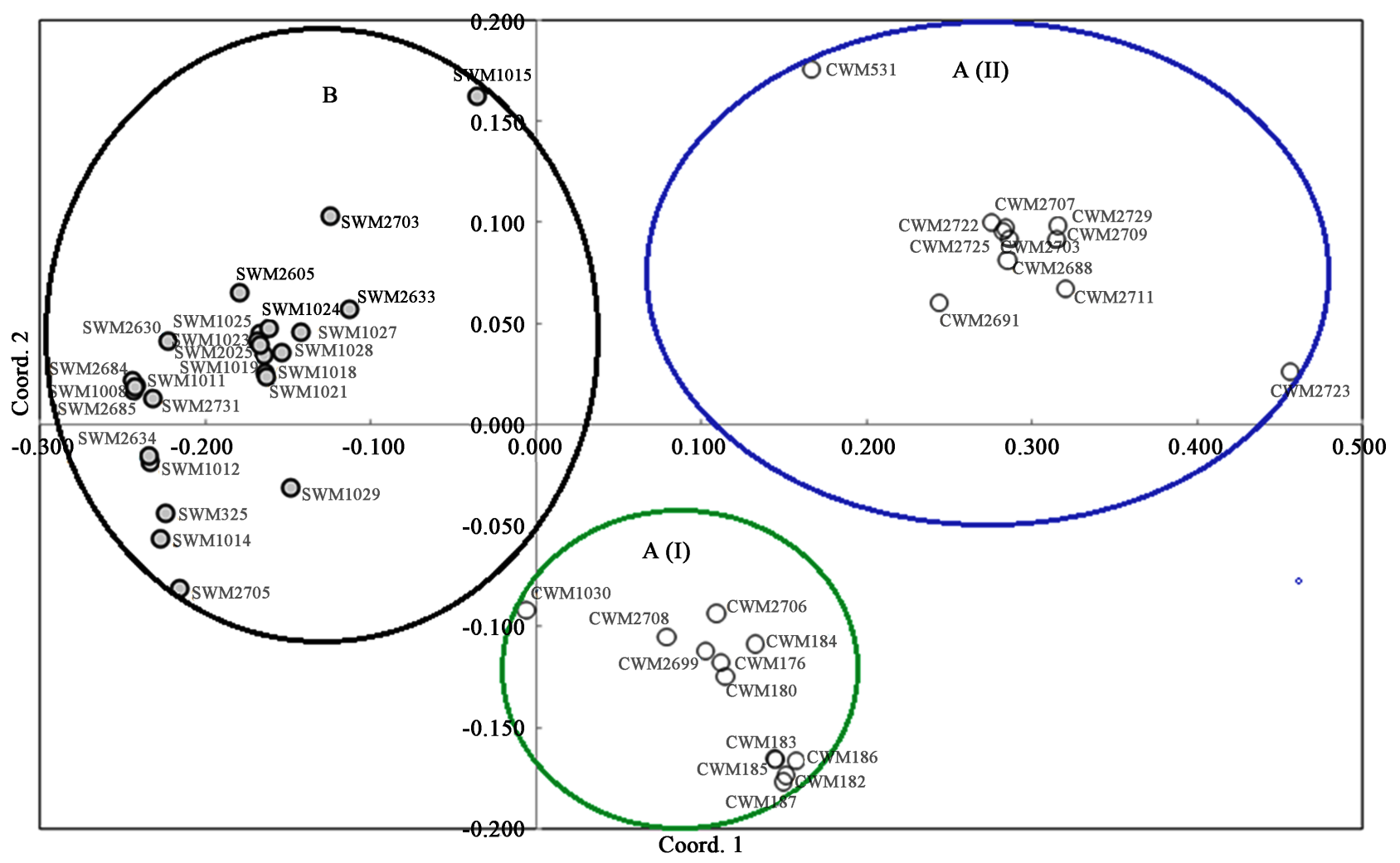

Figure 2. Principal coordinate analysis (PCoA) for Genebank accessions.

\section{Discussion}

The nine loci used in this study where chosen based on previous information about their ability to produce unambiguously scored fragments and the level of polymorphism [1] [3] [23]. The nine primer pairs presented easily interpreted polymorphic amplification (Table 3). A total of 49 alleles were detected on the nine microsatellites analysed. The number of alleles per locus ranged from 2 (MCPI-14 to 13 MCP-07), with an average of 5.4 alleles per locus on 48 watermelon accessions that is, 23 cow melons and 25 sweet watermelons (Table 3 ).

The number of microsatellite markers capable of detecting polymorphism in this study was higher than reported by [1], who produced a total of 43 alleles with an average of 4.8 alleles per locus with the same number of SSR primer pairs. The results from this study were higher possibly due to better variability among the samples than the one used by [1]. Similarly, these results were higher compared to the results reported by [9] of 4.7 alleles per locus, when seven SSR markers were assessed in 33 water melon accessions, including Citrullus lanatus var. lanatus, C. lanatus var. citroides and C. colocynthis. Furthermore, the allele mean described was higher than the results reported by [10], [23] and [30] who found 3.6, 2.8, and 3.9 alleles per locus. However, the average alleles per locus for this study was lower than reported by [31], where 72 alleles were detected with a mean of 7.2 per locus evaluated from 10 SSR markers. According to [32], the application of highly polymorphic markers may lead to a slight overestimation of the diversity. 
According to [33], the Polymorphic Information Content (PIC) is said to be an indicative of the marker quality in genetic studies. The PIC with value greater than 0.5 is considered very informative, with values between 0.25 and 0.50 , medium informative, and values lower than 0.25 less informative. The PIC ranged from 0.73 in locus MCPI-14 to 0.98 in locus MCPI-07 (Table 3). The results from this study had very high PIC value with the mean 0.87 suggesting to be very highly informative.

Analysis of molecular variance within and among accessions of watermelons revealed that only $39 \%$ of the total variation resided between these two groups (cow-melons and sweet watermelons), 24\% between accession within groups and $37 \%$ within accessions. The overall $\mathrm{G}_{\mathrm{ST}}$ for between accession differentiation was 0.67 and $\Phi_{\mathrm{ST}}$ AMOVA of 0.63. Calculations carried out separately for differentiation among cow melon and among sweet watermelon accessions, respectively, produced almost similar values $\left(\mathrm{G}_{\mathrm{ST}}=0.55\right.$ and $\left.\Phi_{\mathrm{ST}}=0.54\right)$ for the cow melon and for the sweet watermelon $\left(\mathrm{G}_{\mathrm{ST}}=0.44\right.$ and $\left.\Phi_{\mathrm{ST}}=0.41\right)$. Both the $\mathrm{G}_{\mathrm{ST}}$ and AMOVA $\Phi_{\text {ST }}$ estimates were much higher compared to those reported by [1]. According to [34], the interpretation of $\mathrm{G}_{\mathrm{ST}}$ and $\Phi_{\mathrm{ST}}$ as measures of differentiation may produce nonsensical results when diversity is high.

The grouping of these accessions that were collected from different parts of Zimbabwe as reflected by cluster analysis and principal coordinate analysis shows how farmers exchange their seeds under informal seed exchanges and farmers practices. Farmers like to share their seeds with other neighbouring farmers, in-laws in different villages or province and exchange during seed fairs and sometimes give their daughter some seeds during marriage time. This way the water melons or cow melons are often grown in the more marginal area were they adapt to the agro-ecological conditions without difficulties. The grouping of these accessions together is also indicative of the fact that the sweet water melons or cow melons have reached to different parts of Zimbabwe through seed exchange by farmers. The local seed sources or farmers' local landrace seeds have advantage in that they adapt to agro-ecological conditions of a given area. Previous studies also highlighted the separate groupings between cow-melons and sweet watermelons [1] [3] [35] [36].

The Sub-cluster A (II) (Table 2, Figure 1 and Figure 2) shows that famers are always selecting for better cow melon seeds to mitigate against the effects of climate change. These turn to affect the characteristics of these accessions since the plants are open-pollinated and there is rarely an isolation distance practiced on-farm [1]. Because of this, introgression between sweet water melons and cow melons is enhanced resulting in sub cluster A (II) which looks like a hybridogenous cluster. The fact that the areas in which the accessions making the hybridogenous group share boundaries, but being distantly separated from those from Sub-cluster A (1) postulate to a possible formation of an isolated evolutionary unit. Although [35] highlighted the possible existence of a niche for development of a hybridogenous form, this study seems to provide an elaborate evidence for its existence. 


\section{Conclusion}

In the study an attempt was made to examine the extent of genetic variation present in the commonly cultivated sweet watermelon and cow melon genotypes as well as their precise identification through efficiency of polymorphic SSR primers. The study revealed high genetic differentiation among all the watermelon accessions under study. Furthermore, the Zimbabwean watermelon genetic resources are highly represented by the major two forms, the cow-melons and the sweet watermelons, while showing a possible existence of the hybridogenous watermelon type. The hybridogenous form is made from accessions previously classified as cow melon accessions, but which are developing into an isolated evolutionary unit. This study could therefore be useful in breeding programmes and for broadening the genetic basis of watermelons.

\section{Acknowledgements}

Financial support for this study was provided by the Swedish University of Agricultural Sciences (SLU).

\section{References}

[1] Mujaju, C., Sehic, J., Werlemark, G., Garkava-Gustavsson, L., Faith, M. and Nybom, H. (2010) Genetic Diversity in Watermelon (Citrullus lanatus) Landraces from Zimbabwe Realeved by RAPD and SSR Markers. Hereditas, 147, 142-153. https://doi.org/10.1111/j.1601-5223.2010.02165.x

[2] Schipper, R.R. (2002) African Indigenous Vegetables: An Over-View of the Cultivated Species. Revised Version on CD ROM, Natural Resources International Limited, London.

[3] Mujaju, C., Zborowska, A., Werlemark, G., Garkava-Gustavsson, L., Andersen, S.B. and Nybom, H. (2011) Genetic Diversity among and within watermelon (Citrullus lanatus) Landraces in Southern Africa. Journal of Horticultural Science and Biotechnology, 86, 353-358. https://doi.org/10.1080/14620316.2011.11512773

[4] Fursa, T.B. (1981) Intraspecific Classification of Water-Melon under Cultivation. Kulturpflanze, 29, 297-300. https://doi.org/10.1007/BF02014757

[5] Chomicki, G. and Renner, S.S. (2015) Watermelon Origin Solved with Molecular Phylogenetics Including Linnaean Material: Another Example of Museomics. NeW Phytologist, 205, 526-532. https://doi.org/10.1111/nph.13163

[6] Achigan-Dako, E., Avohou, E., Linsoussi, C., Ahanchede, A., Vodouhe, R. and Blattner, F. (2015) Phenetic Characterization of Citrullus spp. (Cucurbitaceae) and Differentiation of Egusi-Type (C. mucosospermus). Genetic Resources and Crop Evolution, 62, 1159-1179. https://doi.org/10.1007/s10722-015-0220-Z

[7] Gichimu, B.M., Owuor, B.O., Mwai, G.N. and Dida, M.M. (2009) Morphological Characterisation of Some Wild and Cultivated Watermelon (Citrullus $s p$ ) Accessions in Kenya. ARPN Journal of Agricultural and Biological Science, 4, 10-18.

[8] Levi, A., Thomas, C.E., Newman, M., Reddy, O.U.K., Zhang, X. and Xu, Y. (2004) ISSR and AFLP Markers Differ among American Water-Melon Cultivars with Limited Genetic Diversity. Journal of the American Society for Horticultural Science, 129, 553-558. http://journal.ashspublications.org/content/129/4/553.full.pdf + html

[9] Jarret, R.L., Merrick, L.C., Holms, T., Evans, J. and Aradhya, M.K. (1997) Simple 
Sequence Repeats in Watermelon (Citrullus lanatus (Thunb.) Matsum. \& Nakai). Genome, 40, 1297-1306. https://doi.org/10.1139/g97-058 http://www.nrcresearchpress.com/doi/pdf/10.1139/g97-058

[10] Kwon, Y.S., Park, E.K., Lee, W.S., Yi, S.I., Bae, K.M., An, J.S. and Kim, H.Y. (2007) Genetic Assessment of Watermelon (Citrullus lanatus) Varieties Using SSR Markers Developed from Cucurbit Species. Korean Journal of Genetics, 29, 137-146.

[11] Levi, A., Wechter, W.P., Davis, A., Katzir, N., Tadmor, Y.K., Ling, K.S. and Reddy, U.K. (2007) Interspecific Transferability of Watermelon EST-SSR Markers in Cucurbit Species. Hort Science, 42, 1012.

[12] Sheng, Y., Luan, F., Zhang, F. and Davis, A.R. (2012) Genetic Diversity within Chinese Watermelon Ecotypes Compared with Germplasm from Other Countries. Journal of the American Society for Horticultural Science, 137, 144-151. http://journal.ashspublications.org/content/137/3/144.full

[13] Zhang, H., Wang, H., Guo, S., Ren, Y., Gong, G., Weng, Y. and Xu, Y. (2012) Identification and Validation of a Core Set of Microsatellite Markers for Genetic Diversity Analysis in Watermelon, Citrullus lanatus Thumb. Matsum. Nakai. Euphytica, 186, 329-342. https://doi.org/10.1007/s10681-011-0574-Z

[14] Gama, R.N.N.S., Santos, C.A.F., Dias, R.C. and Souza, F. (2013) Molecular Characterisation of Watermelon Cultivars Using Microsatellite Markers. Horticultura Brasileira, 31, 522-527. https://doi.org/10.1590/S0102-05362013000400003

[15] Munisse, P., Jensen, B.D. and Andersen, S.B. (2013) Genetic Differentiation of Watermelon Landraces in Mozambique Using Microsatellite Markers. African Journal of Biotechnology, 12, 5513-5521.

[16] Nantoume, A.D., Andersen, S.B. and Jensen, B.D. (2013) Genetic Differentiation of Watermelon Landrace Types in Mali Revealed by Microsatellite (SSR) Markers. Genetic Resources and Crop Evolution, 60, 2129-2141. https://doi.org/10.1007/s10722-013-9980-5

[17] Uluturk, Z.I., Frary, A. and Doganlar, S. (2011) Determination of Genetic Diversity in Watermelon (Citrullus lanatus (Thunb.) Matsum \& Nakai) Germplasm. Australian Journal of Crop Science, 5, 1832-1836.

[18] Levi, A., Wechter, W.P. and Davis, A. (2009) EST-PCR Markers Representing Watermelon Fruit Genes Are Polymorphic among Watermelon Heirloom Cultivars Sharing a Narrow Genetic Base. Plant Genetic Resources. Characterisation and Utilization, 7, 16-32. https://doi.org/10.1017/S1479262108014366

[19] Levi, A., Thies, J.A., Wechter, W.P., Harrison, H.F., Simmons, A.M., Reddy, U.K., Nimmakayala, P. and Fei, Z. (2013) High Frequency Oligonucleotides: Targeting Active Gene (HFO-TAG) Markers Revealed Wide Genetic Diversity among Citrullus spp. Accessions Useful for Enhancing Disease or Pest Resistance in Watermelon Cultivars. Genet Resources and Crop Evolution, 60, 427-440.

https://doi.org/10.1007/s10722-012-9845-3

[20] Che, K., Liang, C., Wang, Y., Jin, D., Wang, B., Xu, Y., Kang, G. and Zhang, H. (2003) Genetic Assessment of Watermelon Germplasm Using the AFLP Technique. HortScience, 38, 81-84. http://hortsci.ashspublications.org/content/38/1/81.full.pdf + html

[21] Solmaz, I., Sari, N., Aka-Kacar, Y. and Yesim Yalcin-Mendi, N. (2010) The Genetic Characterization of Turkish Watermelon (Citrullus lanatus) Accessions Using RAPD Markers. Genetic Resources and Crop Evolution, 57, 763-771. https://doi.org/10.1007/s10722-009-9515-2

[22] Maggs-Kolling, G.L., Madsen, S. and Christiansen, J.L. (2000) A Phenetic Analysis 
of Morphological Variation in Citrullus lanatus in Namibia. Genetic Resources and Crop Evolution, 47, 385-393. https://doi.org/10.1023/A:1008751319879

[23] Joobeur, T., Gusmini, G., Zhang, X., Levi, A., Xu, Y., Wehner, T.C., Oliver, M. and Dean, R.A. (2006) Construction of a Watermelon BAC Library and Identification of SSRs Anchored to Melon or Arabidopsis Genomes. Theoretical and Applied Genetics, 112, 1553-1562. https://doi.org/10.1007/s00122-006-0258-6

[24] Smith, J.S.C., Chin, E.C.L., Shu, H., Smith, O.S., Wall, S.J., Senior, M.L., Mitchell, S.E., Kresovich, S. and Ziegle, J. (1997) An Evaluation of the Utility of SSR Loci as Molecular Markers in Maize (Zea mays L.): Comparisons with Data from RFLPS and Pedigree. Theoretical and Applied Genetics, 95, 163-173. https://doi.org/10.1007/s001220050544

[25] Peakall, R. and Smouse, P.E. (2006) GenALEx 6: Genetic Analysis in Excell. Population Genetic Software for Teaching and Research. Molecular Ecology Notes, 6, 288-295. https://doi.org/10.1111/j.1471-8286.2005.01155.x

[26] Wattier, R., Engel, C.R., Saumitou-Laprade, P. and Valero, M. (1998) Short Allele Dominance as a Source of Heterozygote Deficiency at Microsatellite Loci: Experimental Evidence at the Dinucleotide Locus Gv1CT in Gracilaria gracilis (Rhodophyta). Molecular Ecology, 7, 1569-1573. https://doi.org/10.1046/j.1365-294x.1998.00477.x

[27] Nei, M. (1977) F-Statistics and Analysis of Gene Diversity in Subdivided Populations. Annals of Human Genetics, 41, 225-233. https://onlinelibrary.wiley.com/doi/abs/10.1111/j.1469-1809.1977.tb01918.x https://doi.org/10.1111/j.1469-1809.1977.tb01918.x

[28] Excoffier, L., Laval, G. and Schader, S. (2005) Arlequin ver. 3.0: An Integrated Software Package for Population Genetics Data Analysis. Evolutionary Bioinformatics Online, 1, 47-50. https://www.ncbi.nlm.nih.gov/pmc/articles/PMC2658868/ https://doi.org/10.1177/117693430500100003

[29] Rohlf, F.J. (2005) NTSYSpc: Numerical Taxonomy and Multivariate Analysis System. Version 2.2. State University of New York, New York. http://www.exetersoftware.com/downloads/ntsysguide21.pdf

[30] Guerra-Sanz, J.M. (2002) Citrullus Simple Sequence Repeats Markers from Sequence Databases. Molecular Ecology Notes, 2, 223-225. https://doi.org/10.1046/j.1471-8286.2002.00200.x

[31] Mashilo, J., Shimelis, H. and Odindo, A. and Amelework, B. (2017) Genetic Diversity and Differentiation in Citron Watermelon (Citrullus lanatus var. citroides) Landraces Assessed by Simple Sequence Repeat Markers. Scientia Horticulturae, 214, 99-106. https://doi.org/10.1016/j.scienta.2016.11.015

[32] Torutaeva, E., Asanaliev, A., Prieto-Linde, M.L., Zborowska, A., Ortiz, R., Bryngelsson, T. and Garkava-Gustavsson, L. (2014) Evaluation of Microsatellite-Based Genetic Diversity, Protein and Mineral Content in Chickpea Accessions Grown in Kyrgyzstan. Hereditas, 151, 81-90. https://doi.org/10.1111/hrd2.00042

[33] Botstein, D., White, R.L., Skolnick, M.S. and Davis, R.W. (1980) Construction of a Genetic Linkage Map in Man Using Restriction Fragment Length Polymorphisms. American Journal of Human Genetics, 32, 314-331. https://www.ncbi.nlm.nih.gov/pmc/articles/PMC1686077/

[34] Jost, L. (2008) $G_{\text {st }}$ and Its Relatives Do Not Measure Differentiation. Molecular Ecology, 17, 4015-4026. https://doi.org/10.1111/j.1365-294X.2008.03887.x

[35] Mujaju, C., Werlemark, G., Garkava-Gustavsson, L., Smulders, M.J.M. and Nybom, H. (2012) Molecular and Farmer-Based Comparison of a Wild-Weed and Landrace 
Complex of Watermelon in Zimbabwe. Australian Journal of Crop Science, 6, 656-661. http://www.cropj.com/mujaju_6_4_2012_656_661.pdf

[36] Mujaju, C. and Nybom, H. (2011) Local-Level Assessment of Watermelon Genetic Diversity in a Village in Masvingo Province, Zimbabwe: Structure and Dynamics of Landraces Onfarm. African Journal of Agricultural Research, 6, 5822-5834. 